\title{
Reducing the health risks of severe winter weather among older people in the United Kingdom: an evidence-based intervention
}

\author{
CLAIRE GASCOIGNE*, KEVIN MORGAN*, HARRIET GROSS $\dagger$ \\ and JAMES GOODWIN:
}

\begin{abstract}
Excess winter morbidity and mortality among older people remain significant public health issues in those European countries which experience relatively mild winter temperatures, particularly the United Kingdom (UK), Ireland, Portugal and Spain. In the UK, episodes of severe winter weather, when ambient temperatures fall below $5{ }^{\circ} \mathrm{C}$, are associated with peaks in general practitioner consultations, hospital admissions, and cardiovascular deaths among those aged over 65. While research indicates that such health risks could be substantially reduced by the adoption of appropriate behavioural strategies, accessible and credible advice on how older people can reduce risk during 'cold snaps' is lacking. This paper describes a programme of research that aimed: (a) to translate the relevant scientific literature into practical advice for older people in order to reduce health risk during episodes of severe winter weather; and (b) to integrate this advice with a severe winter weather 'Early Warning System' developed by the UK Met Office. An advice booklet was generated through a sequential process of systematic review, consensus development, and focus group discussions with older people. In a subsequent field trial, a combination of the Met Office 'Early Warning System' and the advice booklet produced behavioural change among older people consistent with risk reduction. The results also show that long-held convictions about 'healthy environments' and anxieties about fuel costs are barriers to risk reduction.
\end{abstract}

$\boldsymbol{K E Y} \boldsymbol{W} \boldsymbol{W} \boldsymbol{D} \boldsymbol{S}$ - excess winter mortality, fuel poverty, health policy, public health, older people.

* Division of Psychology, School of Sport, Exercise and Health Sciences, Loughborough University, Loughborough, UK.

$\dagger$ Department of Psychology, University of Lincoln, Lincoln, UK.

\$ Age Concern and Help the Aged, London, UK. 


\section{Introduction}

Seasonal variations in morbidity and mortality rates have long been recognised in the United Kingdom (UK) (e.g. Guy I858), with peaks generally seen in the colder months, particularly among those aged 65 and over (e.g. Aylin et al. 200I; Wilkinson et al. 2004). While such temperature-related vulnerability has fallen steadily throughout the 2oth century (Carson et al. 2006), the continued impact of winter weather on the health of older people (those aged 65 and over) is clearly reflected in UK National Health Service (NHS) activity levels. Hospital admissions for respiratory conditions (Elliot, Cross and Fleming 2008) and ischaemic heart disease (McGregor 2004) increase substantially during winter months, while general practitioner consultations for respiratory tract infections can increase by as much as 19 per cent for every one degree drop in mean temperature below $5{ }^{\circ}$ Celsius (Hajat, Kovats and Lacowycz 2007).

The vulnerability of older people to severe winter weather is also shown in 'excess winter mortality' which, despite improvements in later-life health, remains a major public health issue in the UK. ${ }^{1}$ In a recent comparison of I4 European countries covering the period I988-I997, Healy (2003) found the highest levels of excess winter mortality tended to be in those countries where average winter temperatures are relatively mild - the UK, Ireland, Portugal and Spain. UK average winter mortality during this period was I8 per cent above the autumn/summer level, representing 37,0oo excess deaths each winter, mostly among older people. Conversely, in those European countries which experience more severe (i.e. colder) winter weather (e.g. Germany, Sweden), excess winter mortality is substantially lower (Healy 2003). Indeed, temperature emerges as the key climatic factor associated with negative health outcomes in winter, with humidity, rain, wind and hours of sunshine only weakly, or even inversely related to excess winter mortality (Aylin et al. 200I; Healy 2003).

This apparently paradoxical relationship between the severity of a country's winter weather (as indexed by temperature) and the magnitude of seasonal variations in mortality can be explained by a number of factors. Evidence from community-based studies, for example, shows that winter mortality is strongly associated with both levels of domestic heating (Aylin et al. 200 I) and protection from outdoor cold exposure (Wilkinson et al. 2004). Pan-European analyses, however, continue to show that among the populations experiencing the most severe winters, thermal insulation and heating indoors (e.g. Healy 2003), and outdoor protective clothing (e.g. Donaldson, Rintamäki and Näyhä 200ı; Keatinge and Donaldson I997) tend to be more efficient. In the UK, comparatively poor domestic building standards (Healy 2003), the absence of central heating (Aylin et al. 
200I), inappropriate outdoor clothing (Donaldson, Rintamäki and Näyhä 200I) and lower levels of outdoor activity (Keatinge and Donaldson I997) all contribute to excess winter mortality during very cold episodes ("cold snaps'). Culturally, individuals appear to prepare for average, rather than extreme weather. Where 'average' winter temperatures tend towards the extreme (as in Northern Europe), individuals generally seem better prepared. However, where average winter temperatures tend to be mild (e.g. as in the UK), individuals seem to be less well prepared for occasional episodes of severe winter weather.

Given this, there would appear to be considerable scope for practical and behavioural interventions which could reduce older people's vulnerability to the effects of severe winter weather in the UK. In recent years the UK Met Office (a world-leading provider of environmental and weatherrelated services) ${ }^{2}$ has been working with NHS health-care providers to forecast when patients with certain chronic diseases (e.g. chronic obstructive pulmonary diseases) are more likely to be admitted to hospital (Met. Office 2007). These predictions of elevated risk, linked with interventions to make patients aware of actions they can take to reduce health risks, aim to prevent the progression of the illness. To date this 'health forecasting' has been achieved by drawing data from three primary sources (respiratory infection data, current NHS workload data and meteorological data) to create a sophisticated mathematical model which allows an extremely accurate forecast for several days ahead. Given that older people are most at risk from severe winter weather, the Met. Office objective has been to expand the present health forecasting model to reduce excess winter mortality and morbidity in the age group more generally. In collaboration with the national charity Help the Aged, the Met Office has proposed the development of an 'Early Warning System' which could provide older people living in the community with forecasts that could then trigger appropriate adaptive responses by which to mitigate the health consequences of severe weather (and significantly reduce excess winter morbidity and mortality). While such systems have been developed for exceptionally hot weather, particularly in the United States of America (see Ebi 2007), no such systems have been modelled for use in very cold weather.

As part of the development work for the 'Early Warning System', a pilot study of the views and attitudes of older people and family carers in relation to health aspects of early warning for cold weather events was conducted at Loughborough University (Morgan et al. 2004). A particular (and unresolved) challenge identified in this research was the need to identify and communicate the precise behavioural response needed to prevent adverse health impacts. In other words, having received a warning 
T A B L E I. The sequential stages of the study

\begin{tabular}{|c|c|c|}
\hline Stage & Aim & Output \\
\hline $\begin{array}{l}\text { Stage I: systematic review } \\
\text { to identify appropriate } \\
\text { published and 'grey' } \\
\text { evidence-based advice } \\
\text { literature }\end{array}$ & $\begin{array}{l}\text { To identify appropriate items } \\
\text { of evidence-based advice likely } \\
\text { to reduce health risk during } \\
\text { severe winter weather episodes }\end{array}$ & 28 items of advice \\
\hline $\begin{array}{l}\text { Stage } 2 \text { : consensus } \\
\text { development conference }\end{array}$ & $\begin{array}{l}\text { To assess the utility and } \\
\text { practicality of the } \\
\text { evidence-based advice items }\end{array}$ & $\begin{array}{l}22 \text { items of advice delivered in } \\
\text { booklet form with introduction }\end{array}$ \\
\hline $\begin{array}{l}\text { Stage 3: user consultation } \\
\text { (focus groups) }\end{array}$ & $\begin{array}{l}\text { To assess the face validity, } \\
\text { accessibility and presentation } \\
\text { of the evidence-based advice }\end{array}$ & $\begin{array}{l}\text { Amended booklet containing } \\
22 \text { items of advice with text, } \\
\text { style and content changes } \\
\text { suggested by users }\end{array}$ \\
\hline Stage 4 : field trial & $\begin{array}{l}\text { To assess the effectiveness of the } \\
\text { advice under field conditions }\end{array}$ & $\begin{array}{l}\text { Booklet containing advice and } \\
\text { information suitable for use } \\
\text { with UK Met Office severe winter } \\
\text { weather 'Early Warning Systems' }\end{array}$ \\
\hline
\end{tabular}

of imminent severe winter weather, what precisely should older people be advised to $d_{0}$ in order to reduce their individual health risk.

The programme of research presented here had two objectives: (a) to develop an evidence-based response to episodes of severe winter weather suitable for presentation in booklet form and which, if appropriately practised, could reasonably be expected to reduce severe winter weatherrelated health risk among older people; and (b) in collaboration with the Met Office and Help the Aged, to field trial the 'optimal response' advice booklet within the context of a real severe winter weather episode.

\section{Methods}

The project was carried out in four sequential stages (see Table I): Stage I, a systematic review of the evidence on which advice could be based; Stage 2, a consensus development conference to assess the value and practicality of that advice; Stage 3, user consultations on the style and content of the prototype advice booklet (resulting from Stages I and 2); and Stage 4, a field trial of the resulting advice booklet under real severe winter weather conditions. All stages of the research were approved by the Loughborough University Research Ethics Advisory Committee.

\section{Stage I: The systematic review}

The aim of the review was to identify the scientific evidence that links particular behavioural responses to severe cold weather with demonstrated 
or probable reductions in health risk from severe cold weather (where 'cold weather-related health risk' was defined as: any reduction in health status attributable, even in part, to reductions in ambient temperature below $5^{\circ}$ Celsius). A total of 52 combinations of search terms (e.g. elderly, cold, prevention and cold-stress) were used to identify potentially relevant papers from various databases using Metalib (Exlibris). The search period was $1945^{-2006 .}$

This search of the published literature was combined with a search of the unpublished 'grey' literature (unpublished internal reports, manuscripts in press or in progress and laboratory reports.). Laboratories, individuals and teams likely to be engaged in relevant research activities were identified through the published literature search, the National Health Service Research Directory (http://www.nrr.nhs.uk/) and the Cochrane Library (http://www.nelh.nhs.uk/cochrane.asp), and were invited to submit material. Once identified, all published papers and submitted material were read by members of the research team and retained as 'evidence' only if: (a) the material reported scientific results; (b) the results could translate into practical advice; (c) the resulting advice would be relevant to an older person living at home (or the carer of an older person living at home); and (d) if the advice was adopted, it could reasonably be expected to promote health and reduce risk during severe winter weather.

The search identified over 8 oo papers in the published literature and 35 unpublished reports in the 'grey' literature. Of these, a total of 56 papers/ reports from both searches were considered 'evidence' in the present context. From these a 'long list' of advice, comprising single statements of the required behavioural change, was compiled. This 'long list' was reduced by combining statements where similar or overlapping, or where duplicate advice was offered. This process, conducted by the research team, resulted in 28 single evidence-based advice items using wording judged by the researchers to be appropriate for a public health information booklet. These 28 items are referred to as the 'draft items' in the remainder of this paper.

\section{Stage 2: The expert consensus development conference}

Ideally, all clinical guidelines and health interventions should be grounded in evidence derived from rigorously executed empirical research. In practice, however, 'there are few areas of health care where sufficient research-based evidence exists or will ever exist' (Murphy et al. I998: i). Furthermore, just because the evidence suggests a particular intervention will be effective in terms of a desired health outcome, it will not necessarily be feasible to deliver or advise its use in any individual setting. The 
consensus development approach places relevant information before an expert panel (often comprising scientists, clinicians, service users and lay members) with the aim of achieving agreement on whether proposed guidelines and interventions are feasible, practical and based on credible science (see Murphy et al. 1998). In the second stage of the current project, the 28 'draft items' from the systematic review were placed before a consensus development panel which, in addition to lay representation, included expertise in public health, primary care, epidemiology, physiology and human thermal environments, and health psychology. ${ }^{3}$

Two weeks prior to the meeting the consensus panel members were provided with the $28 \mathrm{draft}$ items, together with a summary of the evidence underpinning each item of advice (cross-referenced to scientific papers). The consensus development panel was held on one working day and chaired by K.M. (am) and H.G. (pm). At the outset it was made clear that the aim was to formulate items of practical advice which could be delivered in booklet form to older people living at home. The panel considered and discussed each of the 28 draft items of advice in terms of: (a) scientific credibility (the strength of the supporting evidence); (b) duplication (where components of advice overlapped); (c) feasibility of adoption (the likelihood that the advice could be translated into practice); and (d) practicality (an assessment of whether the magnitude of anticipated benefit was 'worth' the magnitude of the required behavioural change).

The panel achieved agreement on which of the draft items could remain, which should be rejected, which should be combined or modified, and how the items could best be delivered. This process resulted in 22 items of advice (see Table 2), a title for the proposed booklet, Keeping Warm, Staying Healthy, and the following introductory text:

Cold weather places a strain on your heart. This is because when we are cold, our blood thickens and our blood pressure rises, increasing the risk of heart problems or stroke. Cold weather can also increase the risk of respiratory problems (e.g. colds and flu, chest infections and asthma). This is why it is really important to look after yourself by keeping warm in winter. In this country winter weather contributes to the deaths of over 20,000 elderly people each year. Many of these deaths are from heart attacks and strokes, and could have been prevented. The evidence shows that by taking the simple steps outlined in this leaflet, you can maintain your health and avoid unnecessary illness this winter.

Subsequently the revised items were transferred to a 'mock-up' booklet which was then considered in a series of three focus groups that were formed by members of the intended target population. 
T A B L E 2. Summary of 22 items in the booklet following Stage 2

\begin{tabular}{|c|c|}
\hline Section & Advice (summary only) \\
\hline $\begin{array}{l}\text { At home during } \\
\text { the day }\end{array}$ & $\begin{array}{l}\text { Ideal temperature around } 2 \mathrm{I}^{\circ} \mathrm{C} \text { or } 70^{\circ} \mathrm{F} \text {; keep the heat in (reduce draughts, } \\
\text { close windows, draw curtains after dark); insulate home; don't wait } \\
\text { until you feel cold before you take precautions; wear adequate clothes indoors. } \\
\text { (five items) }\end{array}$ \\
\hline At home at night & $\begin{array}{l}\text { Ideal temperature around } 18^{\circ} \mathrm{C} \text { or } 64^{\circ} \mathrm{F} \text {; close bedroom window; } \\
\text { keep warm in bed; wear comfortable warm nightwear; wear dressing } \\
\text { gown and slippers if you get up in the night. (five items) }\end{array}$ \\
\hline When outdoors... & $\begin{array}{l}\text { Wear hat, gloves and scarf for all excursions (however brief) outside; } \\
\text { avoid standing around waiting in the cold - keep moving; wear layered } \\
\text { clothing (details provided); in severe weather, avoid going out if it's windy } \\
\text { or } i c y \text {. (four items) }\end{array}$ \\
\hline $\begin{array}{l}\text { Looking after your } \\
\text { general health }\end{array}$ & $\begin{array}{l}\text { Keep active in the home; eat at least one cooked meal each day; in } \\
\text { cold weather, increase calcium intake (details provided); maintain vitamin C } \\
\text { intake; take regular warm drinks (even when not thirsty); consume alcohol } \\
\text { cautiously when it's very cold; use extra caution when taking any sedative } \\
\text { medication (e.g. sleeping tablets, antidepressants) - if in doubt, consult your } \\
\text { doctor; get a flu jab, and enquire about a pneumonia jab. (eight items) }\end{array}$ \\
\hline
\end{tabular}

\section{Stage 3: User focus groups}

Given that the advice itself was largely derived from laboratory studies and had never been presented to members of the public in the present format, it was considered important to ask the intended end-users (older people and carers of older people) to examine and discuss the material in terms of its: (a) accessibility (was the material in the booklet understandable?); (b) face validity (did the material in the booklet 'make sense' in relation to the 'Keeping Warm, Staying Healthy' title?); and (b) practicality (was the advice offered in the booklet 'doable'?). Consideration was also given to the presentational style of the booklet. The aim was to include any modifications on which there appeared to be widespread agreement, provided those changes did not alter the scientific credibility of the advice.

The focus-group participants were recruited through advertisements placed in a local newspaper. They were required to be either aged 65 or more years, or the carers of older people, and able to take a taxi from their home to the university. Those who contacted the project office were given information about the research and what the focus groups would entail. Three groups were organised: a younger (Third Age) group (eight men and four women; aged $64^{-7} 7$ years), an older (Fourth Age) group (two men and eight women; aged $7 \mathrm{I}-87$ years), and a carers group (one man and nine women; aged $19-89$ years).

The focus groups were conducted on the university campus, and lasted between $\mathrm{I} .5$ and two hours, with all groups being led by the same 
moderator (C.G.). Prior to the meeting, the participants were provided with a copy of the basic draft booklet which included the proposed 'introductory text' and the advice items agreed by the consensus development panel. The discussions were audio recorded and transcribed verbatim.

Analysis. The primary purpose of the focus groups was to provide feedback on the content and style of the booklet in preparation for the field trial. The analysis of the transcripts therefore centred around: (a) the concept of the booklet and the presentation of its key messages; (b) the acceptability and credibility of the key messages; and (c) the appearance and style of the booklet. To accomplish this, the verbatim transcripts were read and reread carefully and were subject to a thematic content analysis (Dey I993; Ritchie, Spencer and O'Connor 2003). Themes and comments within and across the focus groups were noted, together with suggestions for how the booklet might be improved. Of necessity, a limited subset of the findings is presented below to illustrate the main findings from the groups.

Focus group findings. Overall, the need for such a booklet was widely agreed. Importantly, while much of the advice was regarded as 'common sense', it was not considered either patronising or condescending. The information content of the booklet was also well received, indicating an unmet need to inform people of the actual risks posed by winter weather. As a woman in the Fourth Age group said:

It says here, the blood thickens when we're cold and I hadn't realised that, so that's very useful to know why we do these things, you're not just being told to do it willy-nilly; I like to know why and that I found useful.

Interestingly, the degree of health risk emphasised in the booklet (see text above) was not regarded as overstated or alarmist, with many participants suggesting that such risks may need to be expressed even more strongly.

Regarding style and presentation, the groups made several suggestions. For example, that the print size should be large enough to be read easily, and that temperatures should be expressed in degrees Fahrenheit as well as Celsius. There was also evidence across the focus groups that participants accepted much of the advice within the booklet, as several women in the Third Age Group indicated:

$\mathrm{F}_{4}$ : It's the last sentence I found interesting. So when going outdoors it's ... wrap scarf around your

$\mathrm{F}_{7}$ : Your mouth.

$\mathrm{F}_{4}$ : I don't think we do that ... unless it's really, really cold, but I can see the virtue of it, because then it prevents cold air coming in.

$\mathrm{F}_{5}$ : I think you did that years ago, put the scarf round [your mouth] when it was foggy. 
However, not all items met with such agreement. For instance, the advice to keep bedroom windows closed in winter met with considerable resistance in all three focus groups, with many people believing that having a window open during winter was actually beneficial to health. One man in the Third Age group said:

You know these in the bedroom, it says keep your windows shut, that's one of the worst things out because people who are in a room, breathing air, causing coughs and you want the window open a little bit or have a ... if the room's sealed, it's like sleeping in a box, the colds, flu, then when you go outside, that's what causes the damage.

Much of the resistance to advice that did occur related to cost, and in particular the recommendation to keep the home at a constant $2 \mathrm{I}^{\circ}$ Celsius. During the Third Age group discussion, one man asked:

Could I just ask about paragraph 5, it says if you don't have central heating, think about getting it. You may be entitled to free installation. Brilliant. But I know what an elderly person is going to say is who's going to pay for the gas because they know it's going to cost more.

In general, the participants reflected a sophisticated appreciation of the relevant condensed evidence-based health advice, and an awareness that some messages apply more to some than to others. As a woman in the Third Age group reasoned:

You're aiming at people as a general thing here, aren't you? Trying to get general information out. I mean obviously every individual knows - usually knows about their own particular health things. Things like my feet get cold or my extremities get cold. But that's again, a common sense thing. But if you've given this sort of general information then you can always - that can be a sort of base and you work from there.

Modifying the booklet. Based on the focus group results, several modifications to the content of the booklet were made in order to address the issues that had been raised. For example, because the bedroom window item elicited resistance across all three groups, it was felt necessary to provide a little more information to support the advice. In addition, the font size was increased and some items were re-phrased to make them more accessible. The 22 items of advice were then assembled into a final 'mock-up' booklet using colour formats and graphic material agreed by the full research team and its partners. The front cover of the booklets carried the logos of both the Met. Office and Help the Aged. Two strip thermometers, showing Celsius and Fahrenheit scales, were included in the booklet (one for the bedroom and one for the living room). These booklets, which reflected the scientific evidence base, the views of the consensus conference experts, 
the views and needs of end users, and the style preferred by users and the research team, were then used in a field trial. (A PDF file of this booklet is available from the first author.)

\section{Stage 4: the field trial}

The final stage of the project was designed to field test the advice booklet under realistic conditions among a community-based sample of volunteers in the target age groups, and addressed the following research questions. When used in combination with an actual severe winter weather early warning, are the booklets effective in:

I. raising awareness (and improving knowledge) of the health risks associated with severe winter weather?

2. changing attitudes about the importance of keeping warm during periods of severe winter weather?

3. promoting appropriate behavioural change that likely would reduce risk during periods of severe winter weather?

Recruitment. The participants were recruited through local newspaper advertisements, and were required to be: over the age of 65 ; have access to a telephone; be living within ro miles of Loughborough University; and available at home throughout the two-month 'standby' period. (In the event, one person aged 64 years, the partner of an older volunteer, was admitted into the trial). A total of 37 participants aged $64-83$ years (23 female and I4 male; 24 married participants living with a partner, and I3 living alone) agreed to take part. The majority of the participants (62\%) lived in the town of Loughborough; $3^{8}$ per cent lived locally in rural Leicestershire. All households except one had central heating. The majority of households were owner-occupied with only five of the participants living in rented accommodation (with just one person living in rented sheltered housing). As is common to studies using volunteers, despite broad recruitment criteria, the sample showed higher levels of mobility, health and owner-occupation than a random sample. Similarly, the very frail and the very poor were under-represented, as was ethnicity (no members of ethnic minorities responded to the advertisement).

Field trial design and procedure. The field trial was designed as a two-month monitoring project covering the period I February to 26 March 2007, historically the coldest winter months in England (Met. Office 2009). Participants were initially visited at home, given the booklet (together with an explanation of its use) and advised that, should a period of severe winter 
weather be imminent, they would be informed by telephone by the project office. At each of these home visits the value of the Keeping Warm, Staying Healthy booklet was emphasised at a level equivalent to a public service radio or television broadcast. On each Monday throughout the monitoring period, the Met. Office provided the project with email forecasts of 'normal' or 'elevated' health risk for the following seven days. Information on any elevated health risk was then communicated to participants; the core message delivered to participants was that a cold spell was imminent and therefore they should be referring to the booklet they had been given for advice. When the health risk returned to 'normal', participants were again informed by telephone and told to 'stand down'. As soon as possible after the risk returned to normal, participants were visited and interviewed at home. To accommodate the practicalities of completing 37 home interviews within a reasonable time frame, interviews were conducted over two separate periods of 'elevated risk'.

Two periods of elevated risk occurred during the study monitoring period: the first commenced on 5 February 2007; the second commenced on I8 March 2007.

Field-trial interview procedure. The semi-structured interviews lasted between 30 and 90 minutes, and were audio recorded. Cues were provided to encourage participants to address the five issues of particular interest to the study: risk awareness; attitude change; behavioural change; perceived practicality and feasibility of the booklet; and potential barriers to adopting the advice contained in the booklet. A further topic for discussion included the perceived severity of the cold weather, since this is likely to have determined the participants' response to the booklet. Where participants wished to provide their individual views on any aspect of the trial, these views were recorded uninterrupted.

Analysis of the interview transcripts. Interview recordings were transcribed verbatim and analysed in two ways. Firstly, like the focus group data, all interviews were read and examined for content relating to the areas of particular concern in the trial: awareness, attitudes and behavioural change. These elements of the interview responses were collated and synthesised across the whole data set. Secondly, the transcripts were systematically read, re-read and coded in order to identify themes or concepts following the recommended procedures for thematic analysis in psychological research suggested by Braun and Clarke (2006). Codes were collated into potential themes, which were then reviewed and named. Recurring themes were then clustered under more generic themes 
(e.g. common sense; being prepared). Given the nature of the study, it was considered important to review the whole data set and identify responses which endorsed the value of the booklet and those which did not (in a similar way to negative case analysis). All such responses contributed to the development of the themes.

\section{Results}

Results are presented to reflect the two elements of the analyses: those themes which arose directly from the study questions (i.e. those relating to knowledge and awareness, attitude change, behavioural change, and the perceived practicality and feasibility of the booklet); and those themes reflecting the participants' views of the issues involved, including advice as common sense, and (a key theme highlighting the value of the booklet), reminders and reassurances. An additional theme, cued by the interviewer and prompted by discussion in the focus groups, concerned the perceived severity of the 'cold snaps' that occurred during the monitored period. The perception of cold severity is arguably influenced by the perception of weather-related risk and this theme will be considered first.

\section{'Really' cold weather}

A general view expressed by the interviewees was that neither of the 'cold snaps' had been particularly severe, and many said they had expected the cold weather to be worse than it was, in the light of their own previous experience, as one woman suggested:

Well it's difficult because ... I always think of a cold snap as being like cold snaps that we used to get years ago and they really were cold [laughs].

And a similar point was made by another woman, who clarified why cold seems easier to bear now:

And it didn't seem like ... very bad cold weather because we remember [laughs] years ago when it was extremely cold ... when we didn't have central heating and things like that, you know and err now, you know, it just passes over really without us bothering too much.

Nevertheless, the number of times that the temperature had fallen below freezing, the nights with an air frost, and the amount of snow and wind was detailed by several participants, even while they were acknowledged the relative mildness of the winter compared to winters in their pasts. 
Evidence from the focus groups suggested that the association between cold weather and the increased risk of having a heart attack or stroke was not common knowledge among older people and carers. Most participants were aware that cold weather was associated with an increased likelihood of a respiratory infection and hypothermia; only five explicitly stated that they were aware that cold weather represented a cardiovascular risk. These low levels of awareness are illustrated by the comments from this 67 -year-old man who demonstrated his understanding of more than one health risk:

R: I don't really think it did as a health hazard - I know of course that people do ... die of hypothermia ... either exposed in ... cold weather outside or ... even more so, if they're immersed in cold water.

I: Ok yep ... so was that ... the main risk that you felt cold weather... posed - hypothermia?

R: Prior to this booklet, yes - then I realised, it's not quite ... it can be ... slightly hazardous, even if not quite that extreme.

R: Well, I know when we've had urm ... snow storms, or whatever they're called ... in the Eastern side of ... North America ... people were going out and wanting to clear their cars, and some, middle-aged folks have actually died of heart attack - attempting to clear the snow ... and I thought that was because of they ... unused to exercise.

I: It could be the combination of those -

R: I didn't link that particularly to cold weather ...but of course, this booklet suggests that ... that could well be ... contributory ... cause.

Such examples of knowledge gain from information in the booklet were echoed during the interviews, for many individuals reported that it had helped to raise their awareness and to think more about the risks of cold weather. Despite finding that the booklet appeared to raise levels of risk awareness, however, some participants - including both male and female participants -appeared to have difficulty recognising that these risks applied to them. As a 66-year old man said:

I'm sure I will once I get older, yeah, I'm sure people. ... if somebody read this was in their seventies or eighties they would find this very useful. ... very good advice.

The participants' perceptions of their own susceptibility, and therefore the applicability of the booklet, arose in many of the responses, with a tendency to suggest that the advice would be most useful for 'other people'. These 'other people' who would most benefit would be 'older' (e.g. 'well into their seventies'), frailer and perhaps less knowledgeable than themselves, 
as well as possibly less capable or well supported. A 74-year old woman said:

what worries me if I can just say this is ... the people who live on their own, who haven't got anyone to advise them and that. I think this leaflet might be more use to them than say a couple like us who ... know these things.

This woman went on to specify later in the interview that it is people older than herself - those who do not know the 'rules' of keeping warm - who are most in need of the advice, but several, individuals in their eighties made the same points. Thus the target group for risk advice was repeatedly transposed to others and away from the participants.

\section{Attitude change}

Notwithstanding the distancing of personal risk, participants also indicated that the booklet had significant impact on attitudes towards their increasing susceptibility and their current perception of cold weather and the importance of keeping warm, regardless of their current age.

things that you can put up with when you're younger, I thought that was ok, you know but that just [inaudible] alright, I say I felt a bit cold with the door open or whatever - well I'm getting old with it you know but, now I've decided, you know, it's common sense to do something about it. (F, 67 years old)

The attitude expressed by a number of participants was one of having to accept that they might need to change their behaviour, whether or not they see themselves as at risk.

And ... you just plough on ... and you think 'oh, so what', you know. The ... the effect of the book is that ... it does ... think to yourself ... 'oh well er ... perhaps I ought to have done that - perhaps it would make a difference', you see so urm ... it pulls you up short and you, you concentrate, concentrate on it and um ... well probably act on it really. (M, 79 years old)

For a number of participants, it was clearly the booklet that had led to a change in attitude:

I knew most of it, but urm ... been naughty and not done it you see, but reading that I thought yes you know, we ought to keep warm and, and er dress up. (F, 77 years old) The following extract also provides another example of attitude change; this couple in their late seventies had admitted to turning up the heating during the first period of severely cold weather. The husband's response clearly suggests a change in that he now felt less reluctant to spend money on fuel because he recognised the importance of ensuring that the house was warm enough:

$\mathrm{R}_{2}$ : We put the heating up wasn't it ... so it was...

I: Yeah. 
$\mathrm{R}_{2}$ : But it's been colder but - this is the first time.

$\mathrm{R}_{\mathrm{I}}$ : I'd rather die warm and ... poor, yeah.

I: So it has made you sort of less reluctant to ... spend the money on heating.

RI: Yes because it was worth having.

I: Yeah.

$\mathrm{R}_{\mathrm{I}}$ : That's, that's really what the leaflet did actually $\left(\mathrm{R}_{\mathrm{I}}: \mathrm{M}, 79\right.$ years old; $\mathrm{R}_{2}$ : F, 78 years old)

Such shifts in attitude indicate that, at least for some participants, the messages provided by the booklet were influencing their choices.

\section{Behaviour change}

While there was abundant evidence of behaviour change by the field trial participants, the majority of these changes were subtle (e.g. slipping a coat on when going outdoors to peg out washing; putting on a dressing gown and slippers to make a cup of tea in the morning). Nevertheless even these small changes could have potentially significant benefits in terms of health outcomes if they were widely practised. Some examples of behaviour change involved changing or addressing personal preferences, as Mrs A says:

I don't normally have the radiator on, you know in the bedroom, because I'd rather have a hot-water bottle and breathe in the cooler air but ... no I took on board what you said and I ... just put my radiator on half - you know - so the temperature was quite ... pleasant. $(\mathrm{F}, 72$ years old $)$

Other changes were practical, prompted by the booklet:

Err, not really, no because I did take on board some of the advice in the book, I got urm - instead of having a hole in that door there, for the cats to get in, now I've fitted a cat flap [laughs] and put sealing stuff around my front door and I've, I've put a secondary thing on the letter box. ( $F, 67$ years old)

And this was the case even where expense might be incurred:

You know I were reading the book and I thought well I don't really need a draught excluder cos I've got double glazing, you see, but when it was that cold spell I thought, well, it's not all that hot in here, and I got down and noticed there was a bit of gap between the door and the, you know, carpet and I put my hand under it and you could feel the cold air, and yet all the doors and windows were closed but there's still cold air, you know, coming under that door and I thought B\&Q here we come. (M, 66 years old $)^{4}$

Rather than stimulating substantial or radical change, by increasing awareness the booklet seems to have served to prioritise or justify actions already identified by the participants themselves. 


\section{Barriers/resistance to advice}

Analysis of the interviews also highlighted potential barriers to the advice being adopted, often reflecting concerns about practicality or cost. One practical example was the recommendation to try to keep the house at an even daytime temperature of around 2I ${ }^{\circ} \mathrm{C}$. For some, practicalities made this unachievable, e.g. where people had heating only in certain rooms. On the other hand, notwithstanding the example above, many participants felt reluctant to maintain their home at $2 \mathrm{I}^{\circ} \mathrm{C}$ because of anxiety about the additional cost, maybe because being younger, there would be a longer time over which the increased expense would have to be borne:

R: But also it costs money ... to ... to heat a house like this ... so you tend to keep it - well you mentioned like a heat here ... like a ... which I would have been ... wow - if I'd kept it at 2I or whatever ... that's ... gonna cost you a fortune to ... for a house like this.

I: Okay, so is that something that you think isn't really feasible $\ldots$ for $\ldots$ for yourself?

R: No. (M, 66 years old)

Another item of advice that attracted some resistance from participants concerned the recommendation to keep the bedroom at $18^{\circ} \mathrm{C}$ if possible. Interestingly, reasons for not adopting this particular item included comfort and the psychological need not to be 'closed in':

R: Yeah ... tis a habit - a habit of a lifetime ... my daughter's the sameshe feels claustrophobic without a window open ... it's just something [laughs].

I: It's funny cos you don't feel claustrophobic in ... now when you've not got any windows open...

R: Yeah ... just when you're sleeping - and also I think - I always think well if there's ... a gas leak or anything, at least one of your windows is open somewhere you know ... we knew some - my friend's ... auntie and uncle ... died of carbon monoxide poisoning - they sat in the room with all the doors and windows closed and they'd got a faulty boiler. (F, 74 years old)

A minority view expressed by some in the field trial was that the advice in the booklet came close to being 'nannying' or patronising, especially in conjunction with the various streams of advice given by health and other agencies:

well you see again that's something that I'm afraid I get a little bit tired about. We never used to get weather forecasts that tell you to put a coat on and told you to put a scarf on or be careful. (M, 73 years old) 
Advice as common sense

During the interviews, as in the focus groups, the field trial participants indicated that some of the advice could be construed as common sense. Nevertheless, participants tended not to view the advice as patronising just because they felt it reflected 'common sense'.

R: No I think it was common sense.

I: Common sense, yeah.

R: Yeah ... I think so - I think that - I, I didn't find anything that I thought 'well they're kind of talking down to me' ... no. (M, 66 years old)

Like the focus groups, 'common sense' was generally used by the majority of participants to mean 'appropriate' or 'familiar' and thus acceptable; only a few participants felt 'common sense' advice was patronising, inappropriate or redundant. Even where this was the initial response (e.g. 'to be honest all it is is common sense... it is a little bit condescending') there was a later reflection that there could be individual differences: 'she said common sense, he hasn't got any'.

Reminding and reassuring

Often participants who said they were aware that cold weather was a risk factor for having a heart attack, a stroke or a respiratory illness, would go on to say that the booklet nevertheless provided them with a reminder of this fact and this in itself was useful. A subtheme of reminding was being prepared, so that part of the process of reminding was to undertake appropriate preparations for changes in conditions (as described above).

I think its been useful because urm, we've had such ridiculous weather with it being so mild ... and I think the book, does actually remind you - don't be too, urm, overconfident - you still need your winter clothes you know, don't go getting rid of them. (F, 77 years old)

Similarly, some participants pointed out that an advantage of the booklet was that it reinforced existing behaviour, or existing intentions, for example:

R: Well it reinforced ... it didn't say anything to me 'ooh I'd not done that before' ... but it's saying to me now ... 'I'm doing the - or we're doing the right sort things'.

I: Yeah ... so it was reassuring.

R: It's reassuring $\ldots$ yeah reassuring. (M, 66 years old)

In the context of reminding, there was another theme which emerged from the field trial participant's responses. This was the concept of 'being 
prepared' in general terms, and specifically for cold weather. Indeed when participants were asked to consider whether or not they felt the booklet had missed anything out (bearing in mind that the booklet was evidencebased), some proposed that there could have been more emphasis placed on being prepared for bad weather events, as this woman suggested:

R: I think old people, do take risks ... but if you've got enough food in I think that's what you've got to do - have enough food in.

I: Okay so, so you don't go out in a really cold snap, and also be prepared for it in case you have one-

R: Urm, yes be prepared, yes. (F, 7I years old)

\section{General discussion}

Through Stages I to 3 of this project we aimed to develop an accessible, evidence-based public health booklet offering practical advice to reduce health risk among older people during periods of severe winter weather. The result was an advice booklet with scientific content and a presentational style optimised by the contributions of clinicians, scientists and end users. In Stage 4 of the project, these assumptions of accessibility, practicality and utility were tested under conditions which simulated the intended use of the booklet when combined with actual severe weather warnings. In this final stage the advice booklet (and severe weather warnings) produced evidence of behavioural change consistent with risk reduction among both older people, and the care-givers of older people. In achieving this, it is clear that the information provided in the booklet acted at several different levels.

Evidence from the field study interviews strongly supported the conclusion that, among this self-selected group of older people, the booklets were effective in raising awareness and improving knowledge. Only a minority of the participants expressed prior awareness of cardiovascular risk during winter periods. The remainder clearly admitted that knowledge of this risk was something they had gained from the booklet. The responses also suggested that, in general, the booklet had the useful effect of 'reminding' people of the health risks of severe cold weather. In the context of other information provided during the field interviews, these two outcomes could have far-reaching implications should the 'early warning programme' be adopted nationally.

The view expressed that hypothermia was the principal risk among older people during winter conditions testifies to the success of a campaign completed during the I970s, and clearly indicates the durability of 
messages relating to health risks among older people arising from cold weather. (It was the view of the expert consensus group that hypothermia risk among older people had not been emphasised in public health campaigns for over 20 years). Given this, the present booklet or an equivalent document could fulfil two important roles: (a) providing information to guide personal conduct (and reduce health risk) following a Met Office severe winter weather warning; and (b) introducing lasting change in the public perception of cold weather risk among older people. Nevertheless, the applicability of the approach in bringing about change in more vulnerable or hard-to-reach groups (such as the frail elderly) would need to be addressed in a national trial.

Results from the field interviews also support the conclusion that the booklet influenced changes in attitude among participants, though the operation of such change was often subtle. At its most practical, the booklet appeared to change attitudes in a way that gave some participants 'permission' to behave in a manner which lowered risk during periods of severe winter weather. This effect is exemplified by the man who, having read the booklet, decided to prioritise comfort (and lower risk) over economy, expressing the view 'I'd rather die warm and poor'. On the other hand, some attitudes were simply reinforced by the information (and the emphasis) contained in the booklet. However, this latter effect should not be under-rated. To increase the strength of an attitude is effectively to change the likelihood that issues are considered personally relevant even when others are identified as being more at risk. Thus, to 'validate' already-held perceptions and opinions by an 'official' document can help to shift individuals in the direction of behaviour change.

One of the most unexpected outcomes of the trial was the manner in which 'utility' was reported in the interviews. Intended to mean 'is the booklet considered useful/helpful by the interviewee for the interviewee', many responses, while affirming the booklet's usefulness, identified the beneficiaries of that usefulness as someone else. This, in turn, connected with the more fundamental issue of personal risk perception. Many participants did not see themselves as members of an 'elderly' population, and did not see themselves as particularly at risk. Rather, as described above, they saw the value of the information provided in terms of its usefulness to others who were elderly and at risk, and in some cases they had in mind partners or friends with health problems. This type of selfperception has clear implications for the presentation of health information, as Yardley et al. (2006) also pointed out. Generic references to 'older people', while seeming to target a specific demographic, may not actually match common self-perceptions, as the examples demonstrated. Minichiello, Browne and Kendig (2000) suggest that health professionals, 
in particular, take a negative view of older people and that while some older people may respond by accommodating to their perception, others actively negotiate alternative images of ageing. Jones proposed that positioning as 'older' is a discursive resource, employed according to the 'local business of the interaction' (2006: 79). This would suggest that the participants' own continued health, and their participation in the study with something to contribute, allowed them to position themselves regardless of age as not 'old' but rather as within the category of active ageing. This characterisation echoes work by Townsend, Godfrey and Denby (2006), whose findings suggest that older people identify other older people as 'those like us' or as 'others' based largely on current health. Townsend, Godfrey and Denby (2006) describe the concept of 'victims' - those for whom health considerations limit engagement or participation - which is very much the representation of the more needy as referred to by our participants. Individuals in the Townsend, Godfrey and Denby (2006) study also described 'heroines', those who overcome other difficulties to remain cheerful. There was less mention of these doughty women in the interviews or focus groups; indeed there was little clear difference between men and women interviewed in our study in terms of their discussion of and attitudes to healthy or risky behaviours. In the light of the participants' comments and the need to promote healthy behaviours, as well as the evidence from other research on ageing, it is worth considering the inclusion of appropriate images and textual cues to encourage those for whom the advice is intended to recognise it as relevant.

Two other barriers (to adopting the advice in the booklet) which emerged during the field trial interviews present more of a challenge: conviction and cost. The first of these is primarily illustrated by the issue of leaving bedroom windows open, with many participants strongly resisting, on grounds of health and comfort, the advice to close these windows. In our view, this firmly held conviction may reflect a legacy of a pre-central heating culture when pulmonary tuberculosis was still dominant in the public consciousness, and 'fresh air' was considered salutogenic (by both the public and health-care providers), and leaving windows open in unheated bedrooms would have made less of a difference to the resulting room temperature. Whatever the reasons behind this conviction, it provides a clear example of a collision between contemporary health advice, and earlier health wisdom. Recognising the strength of such convictions, however, can help in the presentation of advice. In the present example (of bedroom windows), acknowledging the existence of contrary views, offering the advice as a suggestion rather than a command, and providing some additional argument may help to carry the point. 
Finally, advice to maintain temperatures throughout the house, insulate loft spaces, and keep central heating running overnight, while based on sound evidence, inevitably introduce issues of cost constraints. In designing the booklet, and with advice from the consensus conference experts, we were careful to avoid offering impractical advice which would be perceived as unaffordable and insensitive. Nevertheless, the reference to cost implicit in any reference to heating should be recognised in any similar undertaking.

\section{Conclusion}

The project achieved its objective of developing an evidence-based information booklet providing accessible and practical advice on health risk reduction during episodes of severe winter weather. The field trial, supported by three preceding stages of research, showed that such a public health information booklet, reflecting scientific evidence and best practice, can improve knowledge and influence attitudes and behaviour in a manner consistent with reduced health risk among older people during periods of severe winter weather. The involvement of older people both in the development of the booklet and as trial participants provided valuable insights into the ways in which such information may be incorporated into daily routines. It is of interest that, in both the focus groups and the trial interviews, the participants, acknowledged their own age but tended to extend the distance between themselves and negative connotations of being 'old'.

\section{Recommendations for research}

While the present project has demonstrated the feasibility of promoting evidence-based optimal health behaviours among older people during episodes of severe winter weather, the findings also point up the need to address two further areas of research. First, more research is required to assess the impact of such behavioural change on morbidity, mortality and quality of life among older people. The possibility that successful outcomes may differ across subgroups of the older population should also be explored. And second, the finding that some participants regarded themselves as inappropriate recipients of advice aimed at 'older people' also deserves further attention, since it has direct implications for the conduct of any public health initiative aimed at reducing personal risk. 


\section{NOTES}

I Excess winter mortality is defined as the difference between the number of deaths during the four winter months (December to March) and the average number of deaths during the preceding autumn (August to November) and the following summer (April to July).

2 The MetOffice, formerly The Meteorological Office, is the United Kingdom's national weather service.

3 In addition to the present authors, the consensus development conference included:

Dr Paul Wilkinson (Public and Environmental Health Research Unit, London School of Hygiene and Tropical Medicine), Professor George Havenith (Human Thermal Environments Laboratory, Loughborough University), Dr Ken Collins (University College London) and Mr Malcolm Mckie (Gateshead Older People's Forum).

$4 \mathrm{~B} \& \mathrm{Q}$ is a national chain of hardware, decorating and garden supplies supermarkets.

\section{References}

Aylin, P., Morris, S., Wakefield, J., Grossinho, A., Jarup, L. and Elliot, P. 200 . Temperature housing deprivation and their relationship to excess winter mortality in Great Britain, I986-I996. International Fournal of Epidemiology, 30, 5, I го-8.

Braun, V. and Clarke, V. 2006. Using thematic analysis in psychology. Qualitative Research in Psychology, 3, 2, 77-IOI.

Carson, C., Hajat, S., Armstrong, B. and Wilkinson, P. 2006. Declining vulnerability to temperature-related mortality in London over the 2oth century. American Fournal of Epidemiology, I6 r, I, 77-84.

Dey, I. I993. Qualitative Data Analysis. Routledge, London.

Donaldson, G. C., Rintamäki, H. and Näyhä, S. 200ı. Outdoor clothing: its relationship to geography, climate, behaviour and cold-related mortality in Europe. International fournal of Biometeorology, 45, I, 45-51.

Ebi, K. L. 2007. Towards an early warning system for heat events. Fournal of Risk Research, Iо, $5,729-44$.

Elliot, A. J., Cross, K. W. and Fleming, D. M. 2008. Acute respiratory infections and winter pressures on hospital admissions in England and Wales 1990-2005. Fournal of Public Health, 30, I, 91-8.

Guy, W. A. 1858. On the annual fluctuations in the number of deaths from various diseases, compared with like fluctuations in crime and in other events within and beyond the control of human will. Fournal of the Statistical Society, 2 I , 52-86.

Hajat, S., Kovats, R. S. and Lackowycz, K. 2007. Heat-and-cold-related deaths in England and Wales: who is at risk? Occupational and Environmental Medicine, 64, 2, 93-Ioo.

Healy, J. D. 2003. Excess winter mortality in Europe: a cross-country analysis identifying key risk factors. Fournal of Epidemiology and Community Health, 57, ro, 784-89.

Jones, R. L. 2006. 'Older people' talking as if they are not older people: positioning theory as an explanation. Fournal of Aging Studies, 20, I, 79-9I.

Keatinge, W. R. and Donaldson, G. C. 1997. Cold exposure and winter mortality from ischaemic heart disease, cerebrovascular disease, respiratory disease, and all causes in warm and cold regions. The Lancet, 349, I0, I34 I-6.

McGregor, G. R. 2004. Winter North Atlantic Oscillation, temperature and ischaemic heart disease mortality in three English counties. International fournal of Biometeorology, 49, 3, 197-204.

Met Office 2007. COPD Forecasting for Anticipatory Care. Available online at http://www. metoffice.gov.uk/health/copd_forecasting.html [Accessed I7 July 2007]. 
Met Office 2009. UK Climate; 3: Regional Climate of the UK. Available online at http:// www.metoffice.gov.uk/education/secondary/teachers/ukclimate.html\#I.2 [Accessed I9 March 2009].

Minichiello, V., Browne, J. and Kendig, H. 2000. Perceptions and consequences of ageism: views of older people. Ageing and Society, 2o, 3, 253-78.

Morgan, K., Haslam, R., Havenith, G., Brace, C. and Tucker, I. 2004. Forecasting the Nations' Health. Internal Report prepared for Help the Aged, Loughborough University, Loughborough, UK.

Murphy, N. K., Black, N. A., Lamping, D. L., McKee, C. M., Sanderson, G. F. B., Askham, J. and Marteau, T. i998. Consensus development methods, and their use in clinical guideline development. Health Technology Assessment, 2, 3, i-iv, I-88.

Ritchie, J., Spencer, L. and O'Connor, W. 2003. Carrying out qualitative analysis. In Ritchie, J. and Lewis, J. (eds), Qualitative Research Practice. Sage, London, 2r9-62.

Townsend, J., Godfrey, M. and Denby, T. 2006. Heroines, villains and victims: older people's perceptions of others. Ageing and Society, 26, 6, 883-9oo.

Wilkinson, P., Pattenden, S., Armstrong, B., Fletcher, A., Kovats, S. R., Mangtani, P. and McMicheal, A. J. 2004. Vulnerability to winter mortality in the elderly in Great Britain: population based study. British Medical fournal, 329, 7467, 647-51.

Yardley, L., Donovan-Hall, M., Francis, K. and Todd, C. 2006. Older people's views of advice about falls prevention: a qualitative study. Health Education Research, 21, 4, 508-17.

Address for correspondence:

Accepted 15 Fune 2009

Kevin Morgan, Division of Psychology,

School of Sport, Exercise and Health Sciences, Loughborough University, Loughborough LEı 3 TU, UK.

Email: k.morgan@lboro.ac.uk 